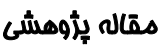

\section{همه تيرى شناسى مسموميت هاى حاد اطفال زير |Y سال مراجعه كننده به بيمارستان امام رضا (ع) بجنورد ( طى Y سال )}

مهدى حارث آبادى'، مجيد صداقت"، محمد على وجدانى"، شهناز احرارى"، نركس طوقيان جهارسوقى '، عبدالوهاب مومنى"

'كارشناس ارشد آموزش يرستارى، گروه برستارى ، دانشعاه علوم يزشكى خراسان شمالى، بجنورد، ايران

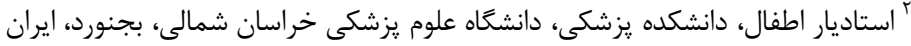

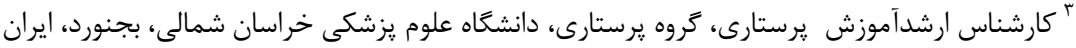

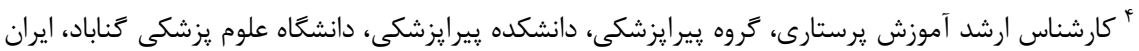

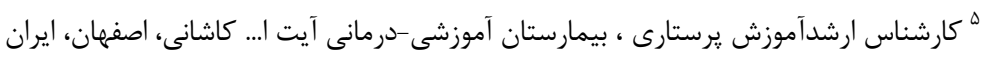

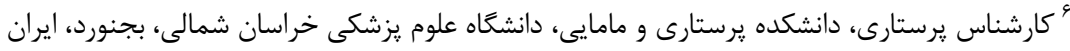

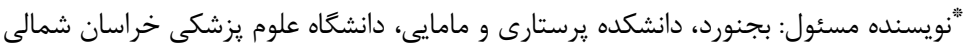
بِّت الكترونيك: mehdiharesabadi@gmail.com

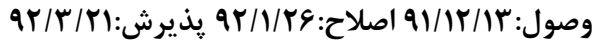

جكيده زمينه و هدف: مسموميت ها ازجمله علل مهرم مراجعه و بسترى شدن كودكان به بيمارستان مى باشد. شيوع و بروز انواع مسموميت ها

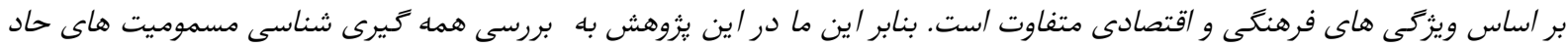

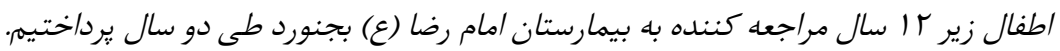

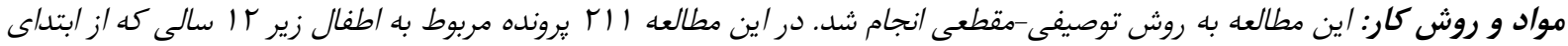

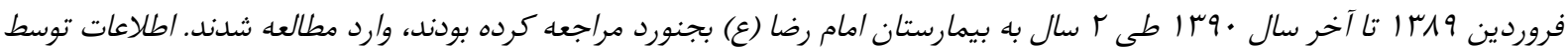
نرم افزار SPSS16 مورد تجزيه و تحليل قرار كرفت.

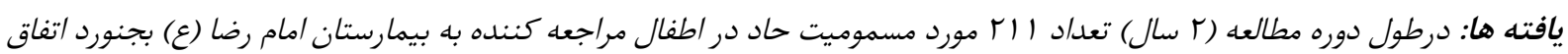

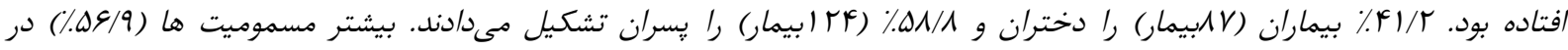

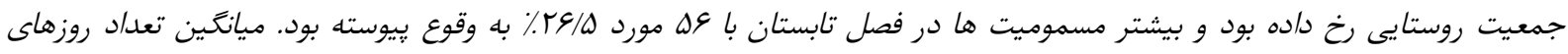

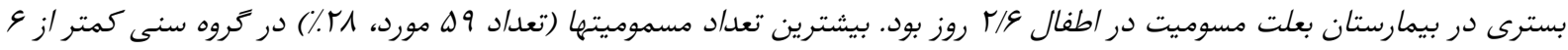

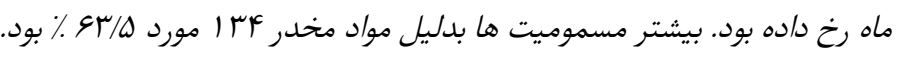

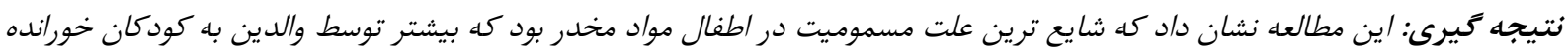

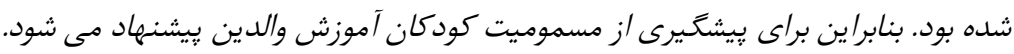

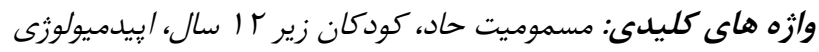

مى توانند باعث آسيب شده و يا تهديد كننده حيات

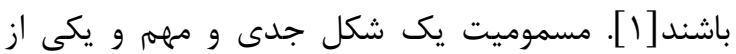
شايعترين علل مراجعه به اورزانس بيمارستان ها در

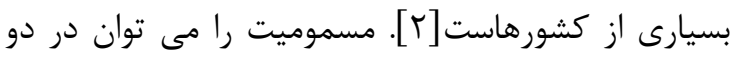
كروه عمدى و غير عمدى طبقه بندى كرد. اكثر مسموميت هاى عمدى در كشورهاى در حال توسعه اتفاق
مقدمه

سم ماده اى است كه معمولاً مى تواند منجر به آسيب و يا مرى يك اركانيسم شود و مسموميت رويدادى است كه طى آن بدن ماده ای را از طريق دهان، تنفس، مخاطات، عروق و غيره جذب كرده؛ اين روند منجر به ايجاد يك ماده رائ سرى عوارض ناشى از مسموميت مى شود كه اين عوارض 


\section{روش كار}

مطالعه حاضر يك يزوهش توصيفى- مقطعى به روش روش بررسى داده هاى موجود' صورت گرفته است. روش كار به ماهـ اين صورت بود كه اعضاى تيم يزوهش بعد از كسب مجوز

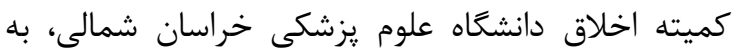
بيمارستان امام رضا (ع) و به بخش مدارك يزشكى مراجعه نمودند. يرونده هاى مربوط به اطفال زير بال

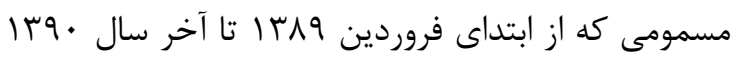

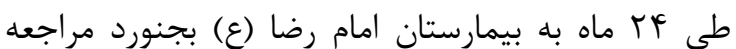
كرده بودند، مورد بررسى قرار گرفت. اطلاعات مورد نياز با كمك فرم ثبت اطلاعات و از زبرونده هاى مسمومين بردين استخراج گرديد. متغير هاى مورد بررسى در اين يزوهش برم شامل متغيرهاى دموگرافيك (سن، جنس، محل سكونت مسمومين) متغيرهاى مربوط به علت و عامل مسموميت،

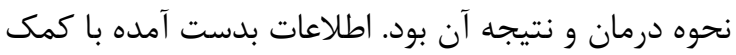
نرم افزار آمارى SPSS نسخه 1 أو و آمار توصيفى مورد تجزيه و تحليل قرار گرفت.

يافته ها

درطول دوره مطالعه (r سال) تعداد Iا ب مورد مسموميت

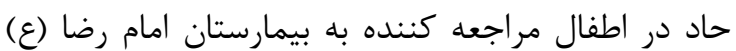

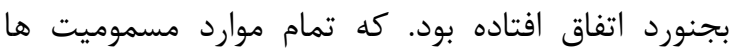
بصورت اتفاقى رخ داده و از اين تعداد ا مورد منجر به

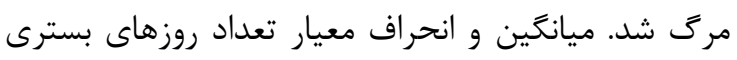

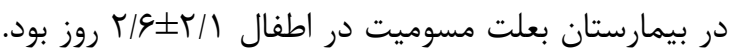

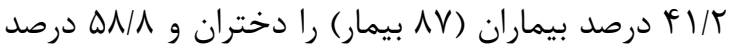

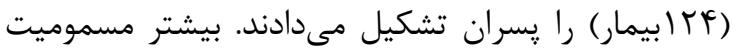
ها در جمعيت روستايى • با مورد بود و بيشتر مسموميت ها در فصل تابستان با وه مورد ه/\& درصد به وقوع پييوسته بود. جدول ا توزيع فراوانى براساس جنس، محل سكونت و فصل را نشان مى دهد.

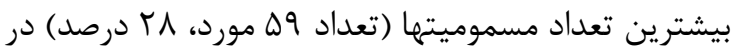
گروه سنى كمتر از 4 ماه رخ داده بود و بعد از آن گروه سنى I- Tال بود. درصد مسموميت بر اساس گروههاى سنى در جدول r نشان داده شده است. توزيع فراوانى مسموميت هاى حاد در اطفال مراجعه كننده به بيمارستان امام رضا (ع) شهر بجنورد نشان داد
مى افتند كه به دليل سميت بالاى مواد و كمبود مراكز يزشكى در دسترس، تعداد زيادى از موارد آن منجر به فوت مى شوند[r]]. مسموميت در همه افراد و در كروه مرها هاى سنى مختلف به صورت روزمره ممكن است رخ دهد قريب به • V\% موارد مسموميت در كودكان رخ مى ده دهد

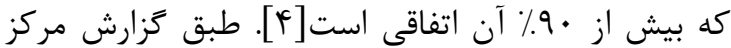
تحقيقات و سلامت آمريكا يكى از علل مهرم حوادث مهلم انه منجر به بسترى در تمام گروه هاى سنى اطفى اطفال، مسموميت است. مسموميت حاد اطفال يك اورزانس شايع و يكى از علل مهرم مرت و مير كودكان خصوصاً در كشور

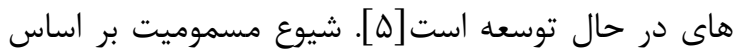
ويززَى هاى فرهنگى و جغرافيايى جوامع مختلف متفاوت است[F]. به عنوان مثال بيشترين علت مسموميت در

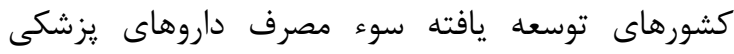
درمانى [ع] و در كشورهاى در حال توسعه استفاده از حشره كش ها (اركانوفسفره ها) است [V]. اخيرا SHO كزارش كرده است كه سالانه فقط بالغ بر سه ميليون موارد

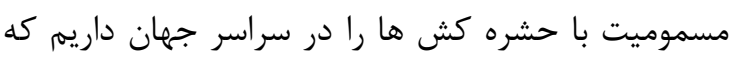
از اين ميان حدود سيصد هزار مورد منجر به فوت مى شوند [^]. افزايش دسترسى و استفاده از مواد شيميايى براى مقاصد مختلف نظير يزشكى، كشاورزى و صنعتى و از طرفى تغيير در شيوه زندكى افراد و رفتارهاى اجتماعى معى منى منجر به افزايش موارد مسموميت و مرگ و مير ناشى از

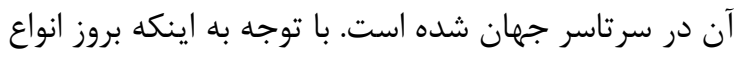

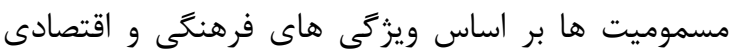
جوامع مختلف متفاوت است و از طرفى تشخيص صحيح و زودهنگام مسموميت و درمان مناسب آن مى تواند حياتى باشد ( و آكاهى از الكوى كلى مسموميت در هر مر منطقه جغرافيايى كمك فراوانى به اين امر مى كند) لذا اين يزوهش با هدف شناسايى ويزگى هاى إيدميولوزيك موارد

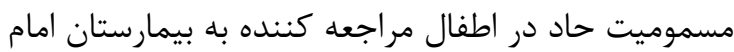
رضا (ع) بجنورد انجام شد، تا بتوانيم با تعيين الكوى مسموميت ها در اين ناحيه جهت تشخيص زودهنگام و كنترل مسموميت و متعاقبا كاهش مرگ و مير ناشى از آن

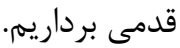




\begin{tabular}{|c|c|c|}
\hline تعداد (درصد) & \multicolumn{2}{|c|}{ مشخصات } \\
\hline$(F \mid / T) \wedge \vee$ & دختر & \\
\hline$(\Delta \Lambda / \Lambda) \mid K F$ & يسر & جس \\
\hline$(F+/ l) 91$ & شهر & $\ldots$. 17 \\
\hline$(\Delta \& / q) \mid r \cdot$ & روستا & من سلون \\
\hline$(r \Delta / 1) \Delta r$ & بهار & \\
\hline$(\Gamma \varphi / \Delta) \Delta \varphi$ & تابستان & \\
\hline$(T \Delta / \zeta) \Delta F$ & ياييز & صل \\
\hline$(Y T / Y) F \wedge$ & زمستان & \\
\hline
\end{tabular}

\begin{tabular}{|c|c|}
\hline \multicolumn{2}{|c|}{ بيمارستان امام رضا (ع) بجنورد } \\
\hline تعداد (درصد) & كروه سنى \\
\hline$(T \wedge) \Delta q$ & كمتر از 9 ماه \\
\hline$(\Lambda / \Delta) \backslash \Lambda$ & צ تاب إه \\
\hline$(19 / 9) \mathrm{Fr}$ & ا تا ץ سال \\
\hline$(I / / \Lambda) T \Delta$ & r اتا سال \\
\hline$(9 / \Delta) \Gamma \cdot$ & ستا ץ سال \\
\hline$(V / I) \backslash \Delta$ & F تا ه سال \\
\hline$(f / T) q$ & ه تا \\
\hline r & بيشتر از ع سال \\
\hline$(1 \cdots) r \mid 1$ & جمع \\
\hline
\end{tabular}




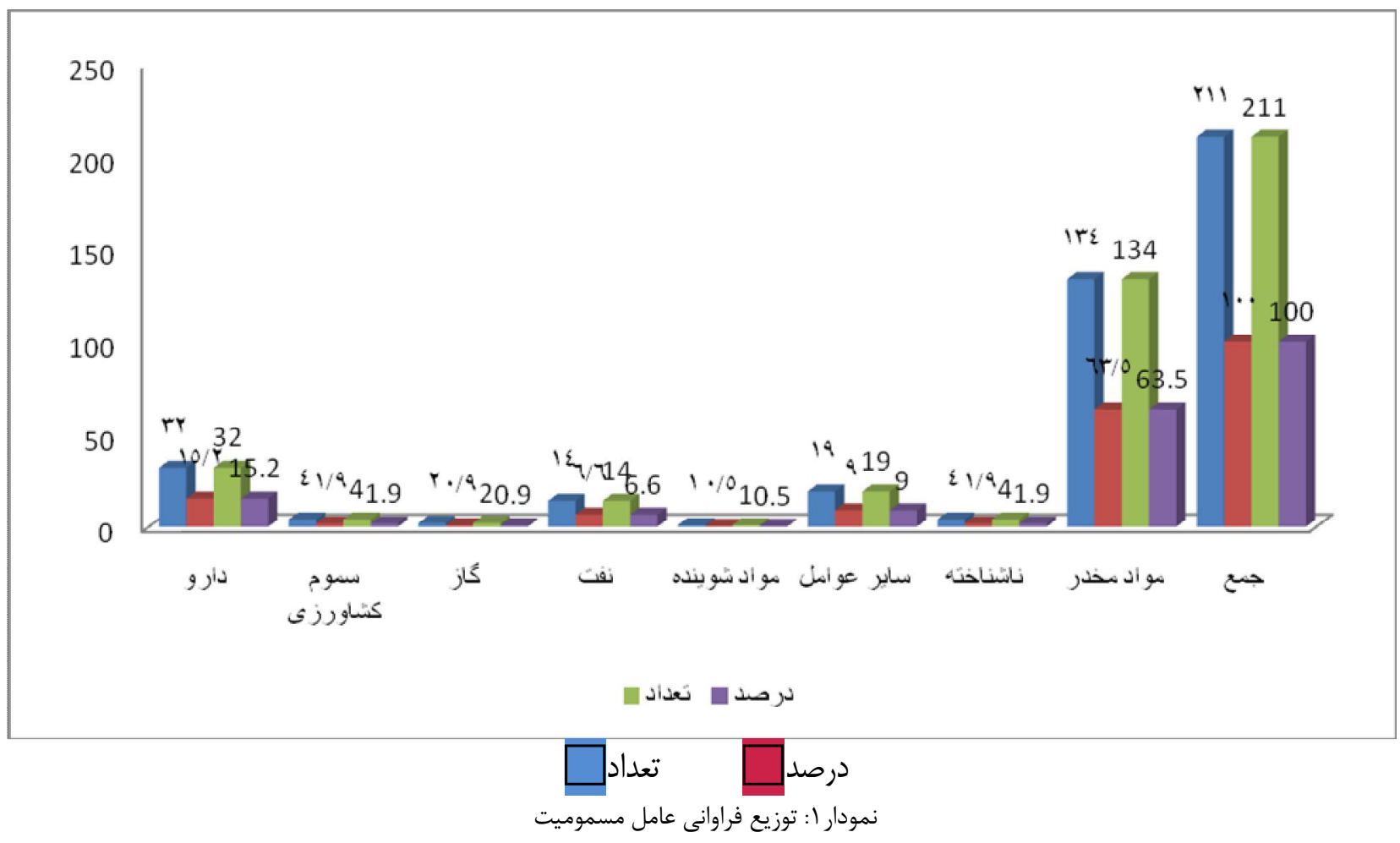

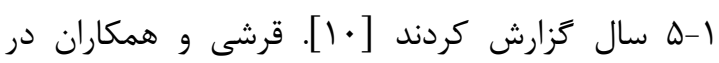

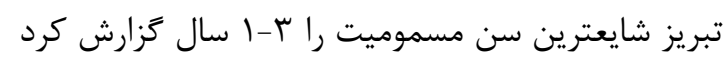

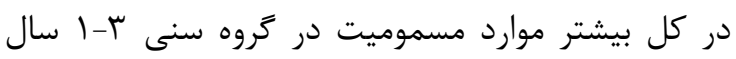

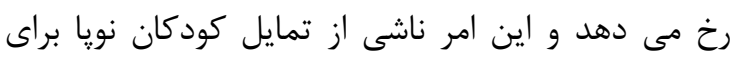

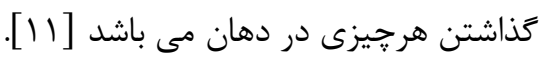

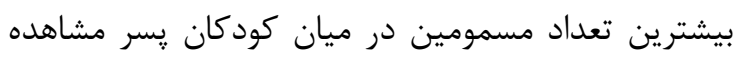

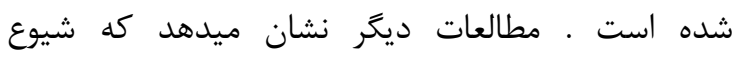

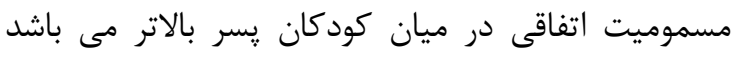

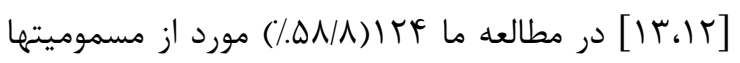

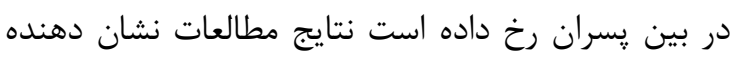

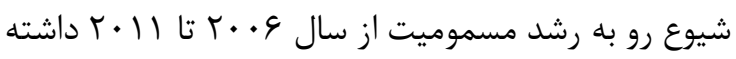
است، اين مطلب نشان مى دهد كه مسموميت در ميان

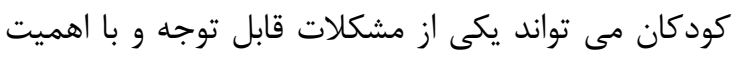
در سيستم بهداشتى درمانى ايران همانند ساير نقاط جهان اندان

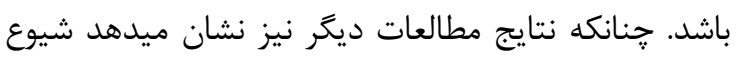

كه بيشتر مسموميت ها بدليل مواد مخدر

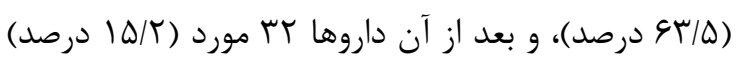

را تشكيل مى دادند (نمودار (1).

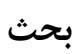

نتايج بدست آمده از مطالعه حاكى از آن است كه بيشترين

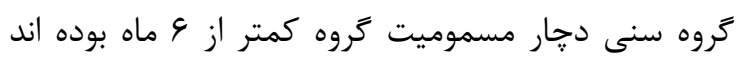

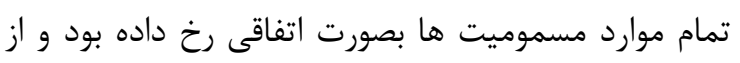

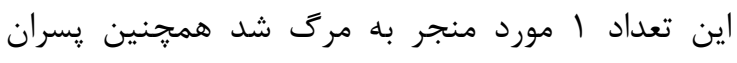

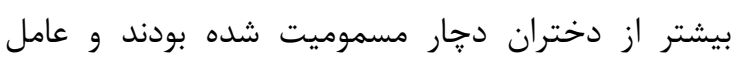
بيشتر مسموميت ها مواد مخدر بوده است.

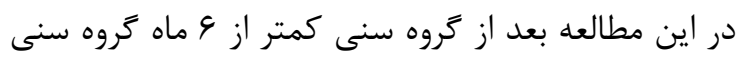

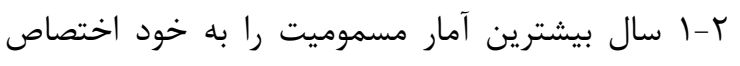
داده بودند. در مطالعه تبار ميرى در اردبيل بيشترين موار موارد

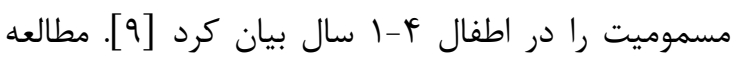
كاشف و هراتى در يزد شايع ترين سن مسموميت را سنين 
موقعيت جغرافيايى كه ايران را در مسير عبور مواد مخدر

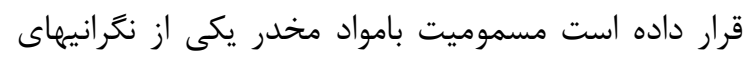

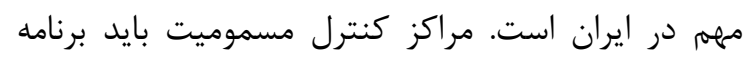

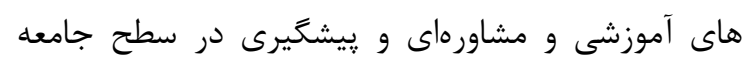

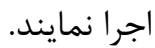

\section{نتيجه كَيرى}

نتايج اين مطالعه نشان داد بيشتر موارد مسموميت ها در

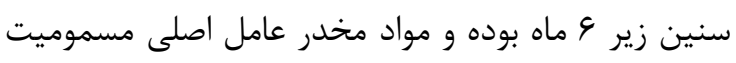

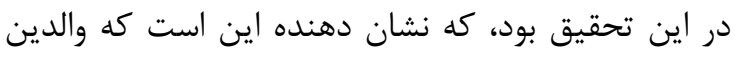

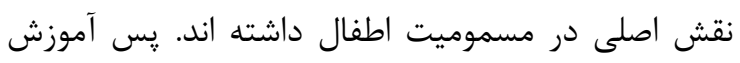
والدين جهت بيشگيرى از مسموميت بيشنهاد مي شود. تشكر و قدردانى

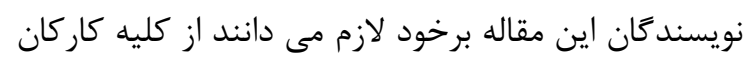

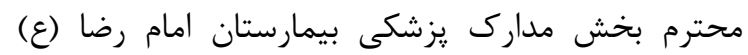

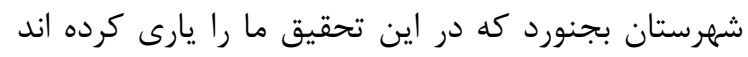

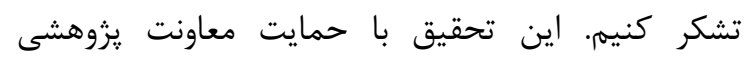

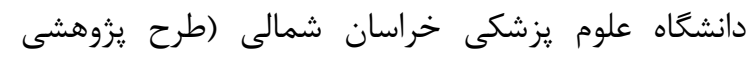

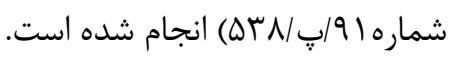

انواع مسموميتها در ميان كودكان رو به افزايش است[If]

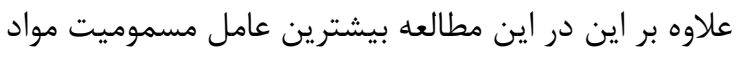
مخدر بوده اند ساير مطالعات نشان ميدهد مواد مخدر

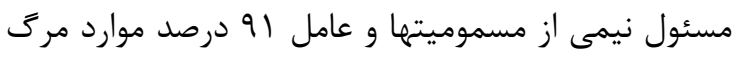
و مير در كودكان در بعضى مناطق ايران مى باشد [1ه].

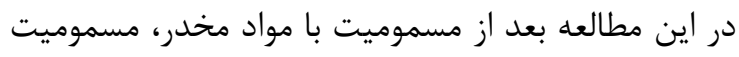

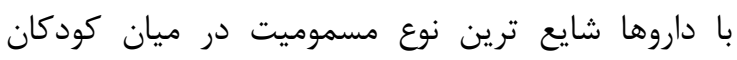

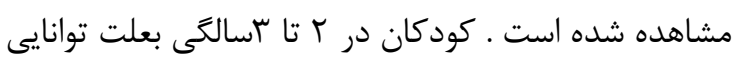
تحرك و كنجكاوى در معرض مسموميت با داروها هستند

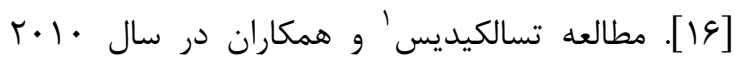

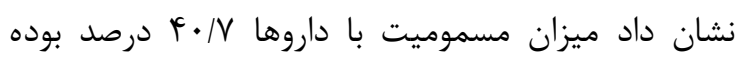

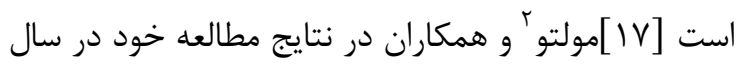

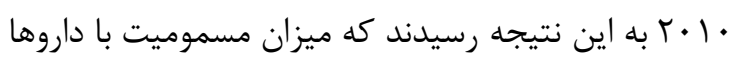

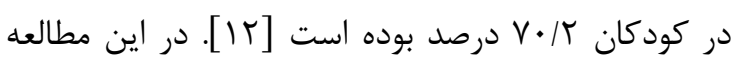

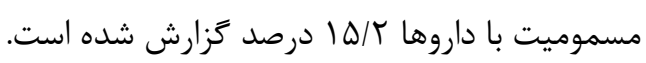

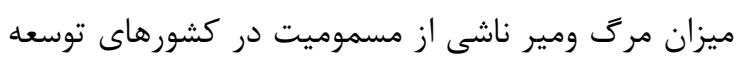

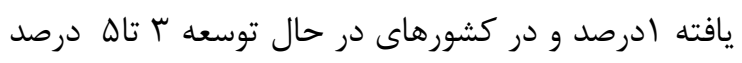

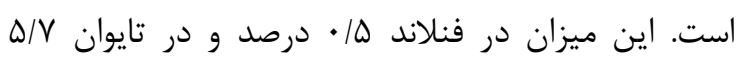

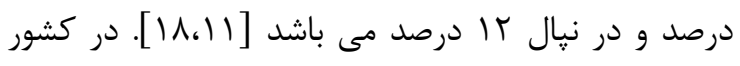

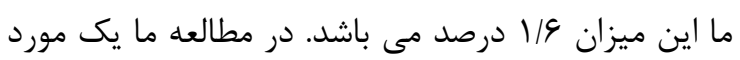

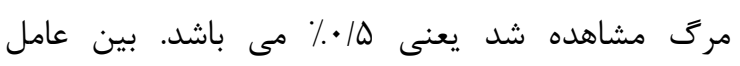

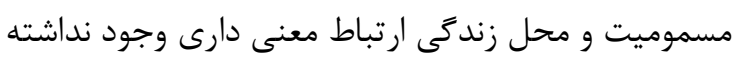

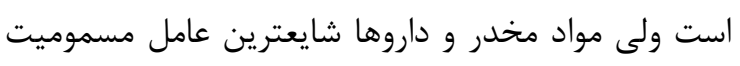
در جمعيت روستايى بوده است. مطالعات نشان مى دهن دهند

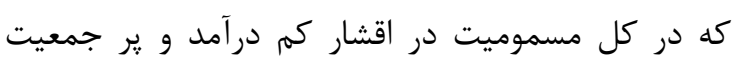
بيشتر رخ مى دهد [19]

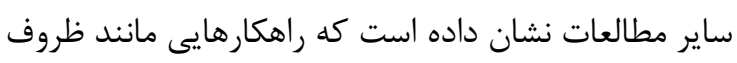

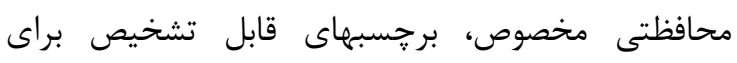

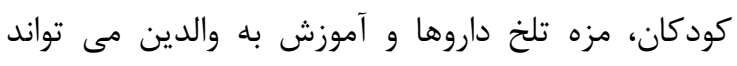
راهكارهاى مفيدى براى جلوكيرى از مسموميت با داروها باشد [r.

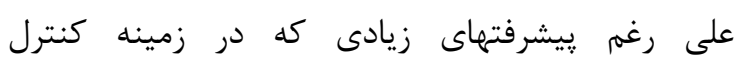
مسموميتهاى اتفاقى در كودكان رخ داده است اين اين مسئله

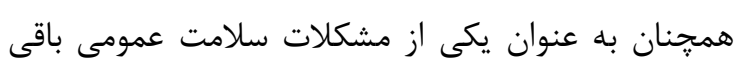

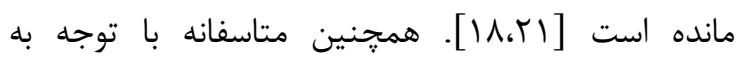




\section{References}

1. Mert E, Gamsiz N. Demographical and etiological and clinical characteristics of poisonings in Mersin, Turkey. Hum Exp Toxicol. 2006; 25; 217.

2. H-L Lee, H-J Lin, ST-Y Yeh, C-H Chi, H$\mathrm{R}$ Guo. Etiology and outcome of patients presenting for poisoning to the emergency department in Taiwan: a prospective study. Human \& Experimental Toxicology (2008) 27: 373-379.

3. Eddleston M. Patterns and problems of deliberate self poisoning in the developing world. QJM 2000; 93:715-31.

4. Al-Jahdali H, Al-Johani A, Al-Hakawi A, Arabi Y, Ahmed QA, Altowirky J, et al. Pattern and risk factors for intentional drug overdose in Saudi Arabia. Can J Psychiatry 2004; 49:331-334.

5. H Khaddam, S. Mohammadian, SH. Colagari. Epidemiology of poisoning in children under 12 years admitted to a tertiary care center in Gorgan during 1378-1376. Journal of Research in Nursing, Number 1 (7)2005:1-7.

6. Shadnia SH, Esmaily H, Sasanian GH, Pajoumand A, Hassanian-Moghaddam $\mathrm{H}$. Abdollahi $M$.Pattern of acute poisoning in Tehran-Iran in 2003. Hum Exp Toxicol 2007; $26 ; 753$.

7. Abdollahi M, Jalali N, Sabzevari O, Hoseini R, Ghanea T. A retrospective study of poisoning in Tehran. $\mathrm{J}$ Toxicol Clin Toxicol 1997; 35: 387-93.

8. WHO in collaboration with UNLP. Public health impact of pesticides used in agriculture. WHO, 1990.

9. Tabar Miri F. Epidemiology of acute poisoning in children Sina Hospital from April 2008 to the end of 2011, in Ardebil. PhD Professional [dissertation]University of Medical Sciences Ardabir. 11.

10.Kashef S, Hani H. One year of acute poisoning in children admitted to emergency wards of Namazi Hospital. Journal of Medical Sciences and Health Services, Yazd University, Summer 1381, 10 (2) :42-46.

11.Qureshi Z, Soltani Ahari H. Acute toxicity studies in Tabriz Pediatric Patients. Ardabil University of Medical Sciences and Health Services, vol3,no 9, sep-dec2003:59-63.
12.Mutlu M, Cansu A, Karakas T, Kalyoncu $\mathrm{M}$ and Erduran E.Pattern of pediatric poisoning in the east Karadeniz region between 2002 and 2006: increased suicide poisoning. Human and Experimental Toxicology . 2010.29(2) 131-136.

13.Nriagu J , Senthamarai-Kannan R, Jamil H , Fakhori M , Korponic S. Lead Poisoning Among Arab American and African American Children in the Detroit Metropolitan Area, Michigan. Bull Environ Contam Toxicol. 2011 Sep;87(3):238-44.

14. Budhathoki S, Poudel P, Shah D, Bhatta , Dutta AK, Shah GS, Bhurtyal K, Agrawal B, Shrivastava MK, SinghNepal MK .Clinical profile and outcome of children presenting with poisoning or intoxication: a hospital based study.Med Coll J 2009; 11(3): 170-175.

15.Bentur Y, Desiatnic Obchinikov N, Cahana A, Kovler N, Bloom-Krasik A, Lavon O, Gurevych B and Lurie Y. Pediatric Poisonings in Israel: National Poison Center Data. Isr Med Assoc J. 2010 Sep;12(9):554-9.

16. Besharat S, Jabbari A and Besharat M. Opium as a Fatal Substance.Indian Journal of Pediatrics, Indian J Pediatr. 2008 Nov;75(11):1125-8.

17.Tsalkidis A, Vaos G, Gardikis S, Kambouri $\mathrm{K}$, Tripsianis G, Man-tadakis E, Paraskakis E .Acute poisoning among children admitted to a regional University Hospitalin Northern Greece. Eur J Public Health 2010; 18 (4): 219223.

18.H Ozdogan1, M Davutoglu, M Bosnak1, M Tutanc and $\mathrm{K}$ Haspolat . Pediatric poisonings in southeast of Turkey:epidemiological and clinical aspects. Hum Exp Toxicol. 2008 Jan;27(1):45-8.

19. Nagi N, Abdulallah Z. Kerosene poisoning in children in Iraq. Postgrad Med J 1995;71:419-422.

20.Randev SH, Grover N, Sharma R, Sharma H. Acute poisoning in children: seven year experience at a tertiary care hospital of north India. Curr Pediatr Res 2011; 15 (1): 65-68.

21.Oprescu F, Peek-Asa C, Wallis A, Young T, Nour D, Razvan M. Pediatric Poisonings and Risk Markers for Hospital Admission in a Major Emergency Department in Romania. Matern Child Health J. 2012 Feb;16(2):495500 . 


\title{
Epidemiologic Study of Acute Poisoning in children aged under 12 years referred to Imam Reza Hospital 2010-2012
}

\author{
Haresabadi $M^{1}$, sedaghat $M^{2}$, Vejdani $M A^{3}$, Ahrari $S H^{4}$, Toghian CHaharsougi $N^{5}$, Momeni $A V^{6}$ \\ ${ }^{1}$ M.Sc of Nursing, North Khorasan University of Medical Sciences, Bojnurd, Iran \\ ${ }^{2}$ Assistant Professor of pediatric, North Khorasan University of Medical Sciences, Bojnurd, Iran \\ ${ }^{3}$ M.Sc of Nursing, North Khorasan University of Medical Sciences, Bojnurd, Iran \\ ${ }^{4} \mathrm{M}$.Sc of Nursing, Gonabad University of Medical Sciences, Gonabad, Iran. \\ ${ }^{5}$ M.Sc of Nursing, Isfahan Ayatollah kashani Hospital, Iran \\ ${ }^{6}$ B.S of Nursing, North Khorasan University of Medical Sciences, Bojnurd, Iran
}

*Correspondence Author:

North Khorasan University of Medical Sciences, Bojnurd, Iran

Email:

mehdiharesabadi@gmail.com

\begin{abstract}
Background \& Objective: Poisoning is one of the most common causes in referred children to hospital. Prevalence and Incidence of poisoning is different based on cultural and economic characteristics of different communities. Therefore, in this study we aimed to assess the epidemiologic of acute poisoning in children cases admitted to Imam Reza hospital of Bojnurd.

Material and Methods: In a cross sectional descriptive study, the required data were collected from the records of patients younger than 12 years referred to Imam Reza hospital during two years (from April 2010 to end March 2012) .Data were analyzed using SPSS-16 software.

Results: 211 children younger than 12 years were studied during two years. 124 (58.8\%) were male and 87 were female (41.2\%) and the most common range of age were under 6 months. 56.9 percent of the children levied in the rural areas and the summer season with 26.5 percent accounted for the most of the poisoning . The mean duration of hospitalization of children was 2.6 day .The most common case was opium poisoning in children with 68.5 percent.

Conclusion: This study showed that the most common cause of poisoning among children were the use of opium given by parents, therefore, parents' instruction is recommended for poisoning prevention among children.

Key word: Acute poisoning, under 12 year children, epidemiology
\end{abstract}

Submitted:3 Mar 2013

Revised:15 Apr 2013

Accepted:11 June 2013 